\title{
KAJIAN 10 HADIS -HADIS MAUDHU POPULER
}

\author{
Haerudin
}

\author{
Universitas Buana Perjuangan Karwwng \\ PGSD, Fakultas Keguruan Dan Ilmu Pendidikan \\ Haerudin@ubpkarawang.ac.id
}

\begin{abstract}
ABSTRAK
Penelitia ini bertujuan untuk mengkaji hadis - hadis palsu (maudhu) yang dipopulerkan oleh sebagian pendak'wah, juga menjelaskan kualitas hadis tersebut dan pendapat - pendapat ulama pada hadis tersebut. Penelitian ini merupakan jenis penelitian deskriptif kualitatif dengan metode yang digunakan yaitu studi kepustakaan (Librari Research) dengan objek penelitiannya 10 hadis- hadis palsu (maudhu). Pengumpulan datanya melalui observasi, catatan lapangan, dokumentasi data yang diteliti dan diperlukan oleh penulis yaitu referensi-referensi atau buku-buku yang menjelaskan tentang 10 hadis hadis yang popular. Dari hasil penelitian yang dilakukan ke- 10 hadis ini merupakan bermasalah di sanadnya dan ada sebagian bermasalah dimatannya. Dari hasil penelitian ini peneliti berharap agar dapat memberikan kontribusi dan manfaat bagi semua pihak-pihak yang terkait.
\end{abstract}

Kata Kunci : 10 Hadis Palsu, Populer

\section{ABSTRACT}

This research aims to examine the false traditions (maudhu) that were popularized by some preachers, also to explain the quality and opinions of scholars on these traditions. This research is a type of descriptive qualitative research with the method used is library research (Librari Research) with the object of research are 10 false traditions (maudhu). The collection of data through observation, field notes, documentation of the data examined and needed by the author are references or books that explain about 10 popular traditions. From the results of research conducted by these 10 traditions is a problem in his sanad and there are some problems in his eyes. From the results of this study the researchers hope to be able to contribute and benefit to all parties concerned.

Keywords: 10 Fake Hadits, Popular

\section{PENDAHULUAN}

Hadits merupakan sumber hukum Islam kedua setelah Al Qur'an, dan ini telah disepakati oleh ulama tokoh - tokoh ummat Islam. Setiap gerak dan aktivitas ummat, harus dilakukan berdasarkan petunjuk yang ada dalam al Qu'an dan hadits. Begitu pula jika ada permasalahan yang yang muncul di tengah tengah masyarakat, tentu haruslah diselesaikan dan dicarikan jalan keluarnya. Cara penyelesaian dan jalan keluar yang terbaik adalah dengan berpedoman kepada Al Qur'an dan Hadits. Namun sangat disayangkan keberadaan hadis yang benar-benar berasal dari Rasulullah saw, dinodai oleh munculnya hadis-hadis maudhu (palsu) 
yang sengaja dibuat-buat oleh orang orang tertentu dengan tujuan dan motif yang beragam, dan disebarkan ditengah-tengah masyarakat oleh sebagian orang dengan tujuan yang beragam pula. Meyakini dan mengamalkan hadis maudhu merupakan kekeliruan yang besar, karena meskipun ada hadis maudlu yang isinya baik, tetapi kebanyakan hadis palsu itu bertentangan dengan jiwa dan semangat Islam, lagi pula pembuatan hadis maudlu merupakan perbuatan dusta kepada Nabi Muhammad saw.

Apalagi dizaman sekarang ini dengan semakin pesatnya teknologi tidak dapat dipungkiri penyebaran hadis maudhu semakin menyebar luas ditengah - tengah masyarakat awam, dan sering juga sebagaian penceramah yang menyebutkan hadis - hadis palsu tanpa menjelaskan kedudukan hadis palsu tersebut, yang menyebabkan orang yang tidak paham tentang hadis menganggap bahwa itu adalah hadis yang benar - benar bersumber dari rasulallah SAW, padahal sudah jelas jumhur ulama - ulama sepakat hadis maudhu itu adalah hadis palsu yang dilarang disebarkan kecuali menjelaskan kedudukan hadis tersebut bahwa hadis itu kedudukannya hadis palsu, oleh karena itu rasul SAW mengancam bagi yang memalsukan hadis dengan sabdanya :

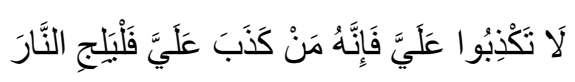

Artinya : Janganlah kamu berdusta atasku, karena sesungguhnya barangsiapa berdusta atasku, maka silahkan dia masuk ke neraka. [HR. Al-Bukhâri, no. 106 dan Muslim, no. 1)

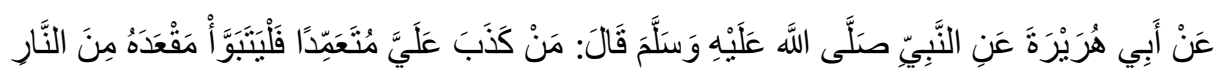

Dalam hadis lain nabi bersabda :

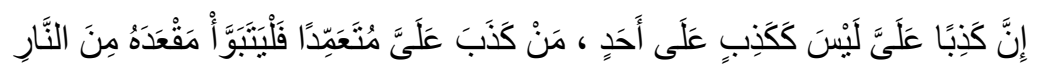

Artinya : Sesungguhnya berdusta atas namaku tidaklah sama dengan berdusta pada selainku. Barangsiapa yang berdusta atas namaku secara sengaja, maka hendaklah dia menempati tempat duduknya di neraka.” (HR. Bukhari no. 1291 dan Muslim no. 4)

Kedua hadis diatas menjelaskan bahwa siapa yang berdusta membuat hadis palsu mengatasnamakan nabi Muhammad SAW maka tempatnya itu dineraka. Dari latar belakang itu peneliti tertarik untuk membuat penelitian “Kajian 10 Hadis - Hadis Maudhu (palsu) Yang 
Popular Dimasyarakat Awam" agar memberi gambaran terhadap masyarakat yang tidak terlalu paham terhadap hadis tentang kedudukan dan hukum hadis - hadis maudhu.

\section{METODE PENELITIAN}

Penelitian ini merupakan jenis penelitian deskriptif kualitatif dengan metode yang digunakan yaitu studi kepustakaan (Librari Research). Maksud dari penelitian deskriptif menurut A. Haedar ( 2011: 26) adalah untuk menguraikan literal ihwal manusia, kejadian, atau suatu proses yang diamati yang bertujuan untuk menyederhanakan realitas sosial yang kompleks agar dapat dianalisis, serta bermanfaat untuk menciptakan konsep-konsep ilmiah dan klasifikasi gejala-gejala sosial dalam masalah penelitian. Sedangkan menurut Judistira K. Gama (2008: 34) Penelitian Kualitatif adalah penelitian yang menghasilkan data deskriptif berupa kata-kata yang tertulis, atau kata-kata lisan dari orang-orang dan perilaku yang diamati. Menurut S. Margono (1997: 36) data yang akan diperoleh dalam penelitian ini adalah : data observasi, data wawancara/angket, dan data dokumentasi. Model analisis data yang digunakan dalam penelitian ini adalah model interaktif yang dikembangkan oleh Miles dan Huberman yang dimulai dengan pengumpulan data, reduksi data, penyajian data, dan penarikan kesimpulan/verifikasi.( Wahyu, 1996: 61). Menurut Kaelan (2010: 134) Studi Kepustakaan dalm arti bahwa data yang menjadi objek penelitian merupakaan bahan bahan kepustakaan. Data yang akan digali adalah hal- hal yang terkait 10 hadis - hadis maudhu. Proses analisis data dilakukan secara terus-menerus di dalam proses pengumpulan data selama penelitian berlangsung. Pengujian keabsahan data dilakukan dengan menggunakan teknik triangulasi.

\section{Waktu Penelitian}

Waktu penelitian dalam penelitian ini selama 7 bulan dari bulan Februari sampai dengan Agustus tahun 2019

\section{Subjek Penelitian}


Subjek dalam penelitian ini dibatasi hanya 10 hadis - hadis maudhu yang popular.

\section{Sumber Data}

Sumber data dalam penelitian ini ada dua yaitu data primer, dalam penelitian ini yang meupakan data primer adalah buku - buku hadis yang terdapat 10 hadis - hadis maudhu. Adapun sumber data sekunder dalam penelitian ini buku - buku dan jurnal - jurnal yang berkaitan dengan objek penelitian.

\section{Teknik Pengumpulan Data}

Karena penelitian ini merupakan Librari Research, yang jenis penelitian kualitatif menurut Sugiono pengumpulan data dilakukan dengan observasi, intervieu, dokumentasi, dan triangulasi.

\section{Teknik Analisis Data}

Metode analisis data yang digunakan dalam penelitian ini bersifat interpretatif. Menurut Kaelen (2010: 169-173) Pendekatan interpretatif (interpretative approach) berarti menyelami pemikiran seorang tokoh yang tertuang dalam karya - karyanya guna menangkap nuansa makna dan pengertian yang dimaksud secara khas sehingga tercapai suatu pemahaman yang benar

\section{Hasil Penelitian}

Hasil penelitian ini akan dipaparkan sebagai berikut :

Hadis pertama

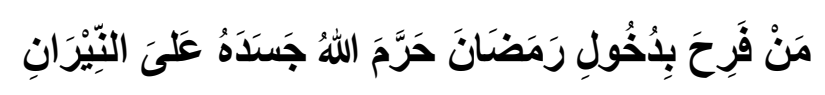

Artinya :

"Barang siapa yang bergembira dengan datangnya bulan ramadhan maka allah SWT mengharamkan jasadnya untuk masuk neraka"

\section{Sumber Hadis}


Hadis ini bersumber dari kitab Durrah al-Nashihin itupun tidak disertai sanad, sanad dalam istilah hadis menurut Mahmud Al tahan (2004:18) secara bahasa artinya yang dijadikan pegangan, adapun secara istilah artinya rangkian perowi - perowi hadis yang sampai pada matan. Jadi hadis ini tidak menyebutkan sanad haditsnya akan tetapi langsung menyandarkan riwayat hadits tersebut pada Rasulullah. Kitab ini merupakan buah karya Utsman Ibn Hasan ibn Ahmad asy-Syakir al-Khubawi wafat tahun $1241 \mathrm{H}$

\section{Kualitas Hadis}

Setelah ditelusuri di dalam kitab-kitab hadits, tidak ada satupun kitab hadis yang menyebutkan hadis di atas. Seperti disampaikan di awal, hanyalah al-Khubawi saja dalam Durratun Nashihin yang menuliskan dan menisbatkannya kepada Rasulullah Saw. Tidak adanya hadis di atas dalam kitab-kitab hadis yang dijadikan refrensi oleh kebanyakn ulama hadis seperti kitab al bukhori, muslim, imam ibnu majah dll, adalah isyarat pertama tentang kepalsuan hadis tersebut. Kemudian al-Khubawi tidak mencantumkan rangkaian sanad atau perawi hadisnya. Tidak adanya sanad dalam hadis tersebut semakin memperkuat kepalsuan hadis tersebut. Sanad adalah unsur terpenting dalam hadis. Sebuah ungkapan tidak bisa disebut hadis jika mata rantai sanadnya tidak sampai kepada Rasulullah Saw. Apalagi ungkapan tersebut tidak ada sanadnya.

Dalam kajian ilmu hadis, model hadis seperti ini masuk ke dalam kategori hadis palsu yang dikenal dengan istilah la ashla lahu, laisa lahu ashlun, la sanada lahu, atau laisa lahu sanad, yang artinya tidak ada sumber dan asalnya. Dengan kata lain istilah ini berarti perkataan palsu di mana Rasulullah Saw tidak pernah menyampaikannya. Maka dari itu, berdasarkan kajian sanadnya, hadis di atas palsu dan tidak bisa diamalkan. Setelah dipastikan kepalsuan hadis tersebut secara sanad, selanjutnya hadis tersebut akan diuji redaksi atau ungkapannya. Kata man fariha (من فرح) di dalam kitab-kitab hadis yang dijadikan rujukan hadits, seperti dalam kitab soheh al muslim, soheh al bukhori dll, ataupun teks - teks hadis yang menerangkan bulan ramadahan tidak pernah bersanding dengan kata Ramadhan, jika dilihat dari ma'na haditsnya juga hadis ini termasuk kategori hadits yang palsu yang termasuk kedalam ciri - hadis palsu yaitu mengandung berita tentang pemberian pahala yang besar untuk perbuatan kecil.

Kesimpulan kajian hadits ini yaitu termasuk hadits yang palsu dilihat dari kajian sanad dan matannya. Prof. KH. Ali Musthafa Ya'qub MA, dalam bukunya, Hadits-hadits Bermasalah di Bulan Ramadhan, menuliskan bahwa hadis dengan teks seperti di atas itu terdapat dalam kitab Durrotun Nashihin, karya Utsman bin Hasan al-Khubawi, yang mana hadis ini memuat amal-amal kecil, sederhana, namun dihargai dengan balasan yang sangat 
besar,dan berlipat ganda. Beliau juga mengkategorikan hadis ini adalah hadis palsu.

\section{Hadis Kedua}

\section{اُطُلْبُهُ العِلْمَ وَلَوْ فِي الصِينِ}

Artinya :

"Carilah ilmu walaupun sampai kenegri cina"

\section{Sumber Hadis}

Hadits ini dsebutkan oleh bebebrapa ulama didalam kitab - kitabnya diantaranya : kitab al-Maqashid al-Hasanah karya al-Sakhawi (w. 902 H), aI Durar al-Muntatsirah fi alAhadits al-Musytahirah karya al-Suyuti (w $911 \mathrm{H}$ ), al-Ghammaz `ala al-Lammaz karya aISamhudi (w. 911 H), Tamyiz al-Tayyib min al-Khabits karya Ibn al-Daiba’ (w. 944 H), Kasyf al-Khafa wa Muzil al-Ilbas karya al-Ajluni (1162 H), Asna al-Matalib karya alHut, dan lain-lain.

\section{Kualitas Hadits}

Hadits Carilah ilmu meskipun di negeri Cina ini diriwayatkan oleh rawi-rawi antara lain, Ibn Adiy (w. 356 H) dalam kitabnya aI-Kamil fi Dhu'afa Rijal, Abu Nu'aim (w. 430 H) dalam kitabnya Akhbar Ashbihan, al-Khatib al-Baghdadi (w. $463 \mathrm{H}$ ) dalam kitabnya Tarikh Baghdad dan al-Rihlah fi Thalab al-Hadits, Ibn Abd al-Barr (w. 463 H) dalam kitabnya Jami' Bayan al-'Ilm wa Fadhlih, Ibn Hibban (w. 254 H) dalam kitabnya Majruhin, dan lain-lain. Sementara sanadnya adalah, mereka semua menerima Hadits itu dari: aI-Hasan bin 'Atiyah, dari Abu 'Atikah Tarif bin Sulaiman, dari Anas bin Malik, (dari Nabi Saw).

Menurut para ulama Hadits seperti al-`Uqaili, al-Bukhari, al-Nasa'i, dan Abu Hatim, mereka sepakat bahwa Abu Atikah Tarif bin Sulaiman tidak memiliki kredibilitas sebagai rawi Hadits. Bahkan menurut al-Sulaimani, Abu Atikah dikenal sebagai pemalsu Hadits. Imam Ahmad bin Hanbal juga menentang keras Hadits tersebut. Artinya, beliau tidak mengakui bahwa ungkapan Carilah ilmu meskipun di negeri Cina itu sebagai Hadits Nabi. Dilihat dari kajian matannya juga tidak benar akan tetapi jika dilihat dri ma'na hadis ini yang dihubungkan dengan mencari ilmu itu artinya ma'nanhya benar,hal ini diperkuat lagi oleh hadis - hadis lain yang bukan hadis maudhu diantaranya : 
diriwayatkan Ibnu Majah, dan dishahihkan oleh Syaikh Albani dalam Shahih wa Dha'if Sunan Ibnu Majah no. 224.

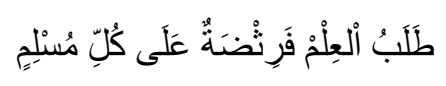

"Menuntut ilmu adalah kewajiban bagi setiap individu muslim."

Adapun secara keseluruhan kualitas hadis ini ada beberapa komentar dari beberapa ulama yang mengomentari hadis ini diantaranya: Imam Ibn Hibban mengatakan, Hadits ini bathil la ashla lahu (batil, palsu, tidak ada dasarnya). Pernyataan Ibn Hibban ini diulang kembali oleh al-Sakhawi dalam kitabnya al-Maqhasid al-Hasanah. Sumber kepalsuan Hadits ini adalah rawi yang bemama Abu Atikah Tarif bin Sulaiman. Hadits tersebut juga ditulis kembali oleh lbn al-jauzi dalam kitabnya al-Maudhu'at (Hadits-hadits palsu). Kemudian alSuyuti memasukan hadis ini kedalam hadis palsu dalam kitabya al-La'ali al-Mashnu'ah fi alAhadits al-Maudhu'ah — sebuah kitab ringkasan dari kitab lbn al-jauzi.

\section{Hadis Ketiga}

\section{النظافة من الايمان}

Artinya :

Kebersihan sebagian daripada iman

\section{Sumber Hadits}

Hadis ini desebutkan dalam kitab idzotun al nasihin itupun tidak menyebutkan sanadnya, dalam kitab Majma' Az-Zawaid karangan imam haistami, yang dalam sanadnya diriwayatkan oleh Ibrahim bin Hayyan.

\section{Kualitas hadist}

Menurut Imam Al-Haitsami di dalam kitabnya Majma’ Az-Zawaid mengatakan bahwa di dalam sanadnya terdapat Ibrahim bin Hayyan yang oleh Imam Ibnu 'Adi (seorang kritikus pakar rawi hadis) mengatakan bahwa hadis-hadisnya (Ibrahim) banyak yang palsu. al Hafidz Al Iraqi memberikan komentar dalam al-Mughni bahwa sanadnya sangat lemah. Secara matan kalimat An-Nadhafatu minal iman tidak valid dan tidak ditemukan siapa yang mengatakan hal ini, ini juga salah satu indikator hadis palsu. Akan tetapi Syekh Yusuf Qardhawi, seorang cendekiawan Mesir sekaligus ulama kontemporer saat ini telah menjawab 
pertanyaan ini dalam website resminya mauqi simahah syeikh yusuf qordhawi Beliau mengatakan,

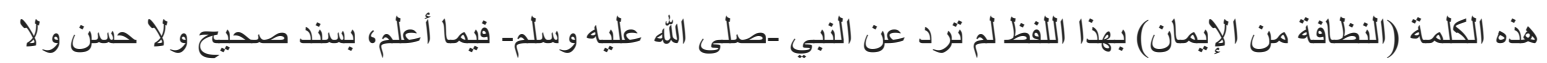

Kalimat ini (An-nadhafatu minal iman) tidak bersumber dari Nabi saw. sebagaimana saya ketahui dengan sanad sahih, tidak hasan, dan tidak pula daif. Tetapi, secara makna kalimat tersebut adalah benar.

\section{Hadis Keempat}

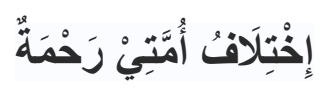

Artinya

Perbedaan dikalangan umatku adalah rahmat

\section{Sumber Hadits}

Hadis ini disebutkan alam kitab Al-Jami’ Ash-Shaghir, Silsilah al Ahadits adh Dhaifah

\section{Kualitas Hadits}

Menurut As Suyuthi dalam kitabnya Al-Jami’ Ash-Shaghir Ini adalah hadits yang tidak ada sanad dan matannya. Munqathi' (terputus sanadnya). Sedangkan Al Albani mengatakan didalam kitabnya Silsilah al Ahadits adh Dhaifah (1/141) bahwa hadits "Perbedaan umatku adalah rahmat" tersebut tidaklah memiliki dasar. Para ahli hadits telah berupaya didalam meneliti tentang sanadnya namun mereka semua tidak mendapatkannya kecuali perkataan Suyuthi didalam “al Jami’ ash Shoghir. Al Manawiy menukil dari as Subkiy, dia mengatakan bahwa hadits tersebut tidak dikenal dikalangan para ulama hadits dan aku tidak menemukan bahwa hadits itu memiliki sanad yang shahih, lemah atau maudhu'. Hal itu ditegaskan oleh Syeikh Zakaria al Anshariy didalam catatannya tentang "Tafsir al Baidhowi” (2/92). (as Silsilah adh Dhaifah juz I hal 134). 


\section{Hahdis Kelima}

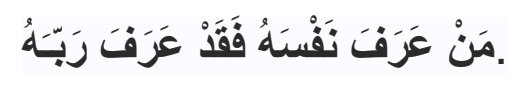

Artinya

Siapa yang mengenal dirinya makadi telah mengenal tuhannya

\section{Sumber Hadits}

Hadis ini disebutkan dalam kitab Al-Hawi lil Fatawa karangan imam suyuthi,

\section{Kualitas Hadits}

Imam As-Suyuthi dalam karyanya Al-Hawi lil Fatawa pada sub bahasan Al-Qaulul Asybah fi Haditsi Man Arafa Nafsahu Faqad Arafa Rabbahu. Terkait persoalan otentisitas, An-Nawawi menegaskan bahwa ungkapan itu tidak mempunyai validitas yang kuat sebagai hadits Nabi. Imam As-Suyuthi mengutip pendapat An-Nawawi sebagai berikut:

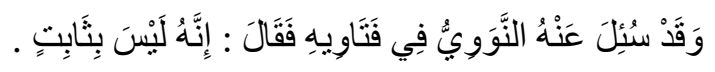

Artinya, "Imam Nawawi pernah ditanya terkait ungkapan tersebut di dalam kumpulan fatwanya, lantas ia menjawab, 'Ungkapan itu tidak mempunyai validitas sebagai hadits Nabi,”’ (Imam As-Suyuthi, 2004, juz II, halaman 288).

Ibnu Taimiyah menilainya sebagai hadits maudhu'. Sedangkan Az-Zarkasyi dalam hadits-hadits masyhurnya mengutip perkataan Imam As-Sam'ani yang menyebutkan bahwa ungkapan itu merupakan perkataan dari seorang ulama sufi terkenal Yahya bin Muadz ArRazi. Adapun Imam As-Suyuthi tidak memberikan komentar apapun terkait kutipan yang ia tuliskan di atas. Kita tidak mengetahui alasan As-Suyuthi tidak menarjih beberapa pendapat tersebut. Tetapi besar kemungkinan pendapatnya tidak jauh berbeda dengan pendapat ketiga ulama di atas sebelumnya. Dari keterangan di atas dapat disimpulkan bahwa ungkapan di atas berkemungkinan besar bukanlah hadits nabi, melainkan hanya perkataan salah seorang ulama yang bernama Yahya bin Muadz Ar-Razi yang terlanjur dianggap sebagai hadits oleh sebagian kalangan. Walaupun maknanya benar, tapi setidaknya pembacaan dua orang ulama hadits di atas, yaitu An-Nawawi dan As-Suyuthi cukup menjadi landasan bagi kita untuk tidak menyebutnya sebagai sebuah hadits, walaupun dari segi makna ia mempunyai cakupan dan kandungan yang sangat dalam dan detail. 


\section{Hadis Keenam}

"Barangsiapa melakukan hubungan suami-istri di malam Jumat (Kamis malam) maka pahalanya sama dengan membunuh 100

Yahudi"

\section{Sumber Hadits}

Hadis tersebut tidak peneliti temukan sumbernya dari refrensi kitab kitab hadis yang dijadikan rujukan oleh ulama hadis, akan tetapi hadits tersebut beredar luas di media - media sosial.

\section{Kualitas Hadis}

Sebagian ulama mengatakan, "Kami belum pernah mendengar satu hadis sahih dalam syariat yang memuat pahala yang sangat banyak selain hadis ini." Karena itu, sangat dianjurkan untuk melakukan semua amalan di atas, untuk mendapatkan pahala yang diharapkan." (AlMirqah, 5:68). Hadits ini termasuk hadits palsu dari sisi sanadnya karna tidak ditemukan sanad hadits dari kitab - kitab hadits manapun yang menyebutkan sanadnya, dari sisi matannya juga hadits ini termasuk kategori hadits yang termasuk ciri - ciri hadits palsu karena memberikan pahala yang sangat besar sekali dari perbuatan yang bisa saja

\section{Hadis ketujuh}

\section{حب الوطن من الايمان}

\section{Artinya : "Cinta Tanah Air Sebagian Daripada Iman"}

\section{Sumber Hadits}

Hadits ini disebutkan dalam kitab al-Maqâshidul Hasanah, al-Asrârul Marfû'ah dan Kasyful

khafâ'

\section{Kualitas Hadits}


Syaikh Muhammad Nashiruddin al-Albani mengatakan, "Hadits ini adalah hadits palsu dan maknanya tidak benar, karena mencintai tanah air, sama seperti cinta kepada diri sendiri, harta, dan lain-lain. Semua ini merupakan tabiat (asal) manusia, yang kecintaan ini (pada asalnya) tidak dipuji dan bukanlah merupakan konsekwensi iman. Bukankah kita mendapati semua manusia memiliki rasa cinta ini, tanpa ada perbedaan antara orang yang beriman dan kafir? (al bani Kitab Silsilatul Ahâdîtsidh Dha'îfah wal Maudhû'ah 2009: 36).

Syaikh Muhammad bin Shaleh al-'Utsaimin mengatakan, "Hadits ini sangat populer di kalangan orang-orang awam (dan disangka) bahwa ini hadits shahih, padahal ini adalah hadits palsu dan dusta (atas nama Rasûlullâh Shallallahu 'alaihi wa sallam ). Bahkan maknanya juga tidak benar, karena cinta tanah air termasuk ta'ashshub (fanatik yang tercela). (Majmû'ul Fatâwa war Rasâil 2009 :49-40)

\section{Hadis ke delapan}

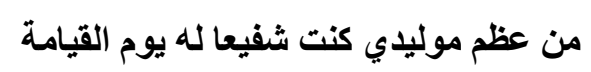

Artinya : "Barangsiapa yang mengagungkan hari kelahiranku, maka kelak aku akan memberi syafaat kepadanya di hari kiamat."

\section{Sumber Hadis}

Hadis tersebut bersumber dari kitab Madarij al-Su'ud karya Syeikh Nawawi alBantani. Namun Syeikh Nawawi al-Bantani juga tidak menyebutkan dari mana sumber asaal hadits tersebut berasal dan siapa perawinya.

\section{Kualitas Hadis}

Abdullah bin Jibrin rahimahullah mengomentari hadis ini "Hadits ini tidak shahih, tidak ada dalam riwayat kitab shahih (Shahih Bukhari atau Muslim) atau kitab sunan. Ini adalah hadits dusta (palsu). ( 


\section{Hadis ke Sembilan}

\section{كاد الفقر أن يكون كفرا}

\section{Sumber Hadits}

Hadits ini dikeluarkan oleh Imam al-Baihaqi dalam kitab "Syu'abul Iman” (no. 6612), Abu Nu'aim Al-Ashbahani dalam "Hilyatul auliyaa"” (3/53 dan 109), Al-Qudha-'i dalam “Musnadusy Syihab" (no. 586), Al-“Uqaili dalam “Adh-Dhu'afaa"” (no. 1979) dan Ibnu 'Adi dalam "Al-Kamil" (7/236), semuanya dari berbagai jalur, dari Yazid bin Aban ar-Raqa-syi, dari Anas bin Malik Radhiallahu'anhu, dari Rasulullah Shallallahu'alaihi Wasallam.

\section{Kualitas Hadits}

Imam Ahmad, Yahya bin Ma'in, an-Nasa-i, ad-Daraquthni Semuanya dinukil oleh Imam Ibnu Hajar dalam kitab "Tahdziibut tahdziib” (32/67-69) mereka berkomentar tentang hadits ini Hadits ini adalah hadits yang lemah, karena dalam sanadnya ada Yazid bin Aban Ar-Raqasyi, dia dinyatakan lemah oleh para ulama Ahli hadits.

Adapun Syaikh al-Albani (dalam Silsilatul ahaadiitsidh dha'iifah wal maudhuu'ah" (4/377, no. 1905). beliau menghukumi hadits ini sebagai hadits palsu, karena dalam sanad yang beliau nukil ada rawi yang suka memalsukan hadits.

Kesimpulannya, hadits ini adalah hadits yang lemah dari semua jalur periwayatannya, bahkan sebagiannya sangat lemah dan palsu, sebagaimana penjelasan di atas.

Hadis ke sepuluh

$$
\text { اعمل لانياكأنك تعيس أبدا واعمل لأخرتك كأتك تموت غدا }
$$

\section{Sumber Hadits}

Hadits ini disebutkan Oleh Imam Al bani dalam kitab As Silsilah Adh Dha'ifah

\section{Kualitas hadits}


Syaikh Al Albani mengatakan: La ashala lahhu marfu'an (tidak ada dasarnya dari Rasulullah). (As Silsilah Adh Dha'ifah, 1/63. No. 8. Darul Ma'arif).

Namun, ungkapan ini memang ada secara mauquf (sebagai ucapan sahabat), yakni ucapan Abdullah bin Umar bin Al Khathab. (Ibnu Asy Syajari, Al Amali, 1/386. Mawqi' Al Warraq) ada juga yang menyebut sebagai ucapan Abdullah bin Amru bin Al 'Ash. (Ibnu Abdi Rabbih, Al 'Aqdul Farid, 2/469. Mawqi' Al Warraq)

Kesimpulannya ini bukan hadist melainkan perkataan sahabta umar bin alkhatab.

\section{KESIMPULAN}

Dalam penelitian ini ke 10 Hadis - Hadis tersebut termasuk hadis palsu, faktor yang membuat hadis itu palsu yaitu karena kesemua hadis tersebut tidak ditemukan sanadnya atau dalam istilah ilmu hadis la ashla lahu (tidak ada asal sanadnya) atau ada yang ditemukan sanadnya akan tetapi dalam sanad tersebut diteumkan perowi yang dianggap lemah atau sering membuat hadits maudhu oleh para ulama hadits, adapun dari segi matnnya ke 10 hadits tersebut banyak yang terindikasi kepada hadis maudhu seperti memberikan pahala yang sangat besar padahal perbuatannya bisa - biasa saja.

\section{DAFTAR PUSTAKA}

Alwasilah, 2011, Pokoknya Kualitatif: Dasar-Dasar Merancang dan Melakukan Penelitian Kualitatif ,Jakarta: Dunia Pustaka.

Ali Musthafa Ya'qub,2014, “ Hadits-hadits Bermasalah di Bulan Ramadhan”, Jakarta: Renika Cipta

Al Sakhawi, 2010, Maqashid al-Hasanah, Bairut:darul fiqr

Al-Suyuti, 2013, aI Durar al-Muntatsirah fi al-Ahadits al-Musytahirah, Bairut:Darul Fiqr

AI-Samhudi,2010, al-Ghammaz `ala al-Lammaz, Bairut:Darul Fiqr

Adiy, 2005, aI-Kamil fi Dhu'afa Rijal, Bairut:Darul Fiqr

Abu Nu'aim , 2013, Akhbar Ashbihan, Bairut:Darul Fiqr

Al-Khatib al-Baghdadi, 2008, Tarikh Baghdad, Bairut:Darul Fiqr

Al-Daiba, 2009, al-Rihlah fi Thalab al-Tamyiz al-Tayyib min al-Khabits, Bairut:Darul Fiqr 
Al-Ajluni, 20007, Kasyf al-Khafa wa Muzil al-Ilbas, Bairut:Darul Fiqr.

.Abd al-Barr, 2009, Jami’ Bayan al- 'Ilm wa Fadhlih, Bairut:Darul Fiqr

Alfatih Suryadilaga, dkk, 2010“Ulumul Hadis”, Yogyakarta: Teras,

Al-Khubawi, 2007, Durroh Al nsihin, Semarang: toha putra

Bukhori. 2002, Al jami Al sahih, Dimaskus, Daar Ibnu Katsir.

Kaelen, 2010, Metodologi Penelitian Agama Kualitatif Interdisipliner, Yogyakarta:

Paradigma

Albani, 2007, Silsilah Alahadis addhoifah, Bairut:Darul Fiqr

Muslim,. 2006, Sohih AL muslim, Mesir, Daar Thayyibah.

Mahmud Al tahan,1996, Taisyir Al musthalah Al hadis, Maktabah Maarif, Riyadh.

S. Margono, 1997, Metodologi Penelitian Pendidika, Jakarta: Renika Cipta.

Yudistira, 2008, Dasar dan Proses Penelitian Sosial, Bandung; Primaco Akademika.

Wahyu, 1996, Pedoman Penelitian Pendidikan, Bandung: Tarsito.

Hasbi Ashshiqqiqy,2010, Sejarah dan Pengantar Ilmu Hadis: 255 ,Jakarta: Renika Cipta

Hasan Asyeari Ulamai, 2006, “Melacak Hadis Nabi Saw, Rasail”, Semarang

Ibn Hibban, 2005, Majruhin, Bairut:Darul Fiqr

Imam As-Suyuthi, Al-Hawi lil Fatawa, 2004, Beirut, Darul Fikr,

Kementerian Agama RI, 2016“Al-Qur'an dan Terjemahan”,Cet. I; Bandung: Cordoba.

Muhibbin Noor,2003 “Kritik Kesahihan Hadist Imam Bukhori”, Yogyakarta: Waqtu,

Muhammad Mustafa al-A"zami, Manhaj al-Naqd „Inda AlMuhadditsin: Nasy“atuh wa

Muhammad Nawawi bin Umar Al-Jawi, Tausyaih "Alaa Ibnu Qasim”, (Jakarta: Dar AlKutub Al-Islamiyah, 2002)

Nuruddin Itr, Alih Bahasa oleh Drs. Mujiyo, “Ulumul Hadis”, (Bandung: PT Remaja) Nawir Yuslem, "Sembilan Kitab Induk Hadis”, (Jakarta: Hijri Pustaka Utama, 2006)

Sohari Sahrani, “Ulumul Hadis”, (Jakarta: PT Ghalia Indonesia, 2010)

Yusuf al-Qardhawi, “Kaifa Nata'amal Ma'a as-Sunnah anNabawiyyah”,(al-Qahirah:Darul as-Syuruq, 2002). 
Haerudin Vol 4 No 2

ISSN : 2541-6995

E ISSN : 2580-5517

$\mathbf{4 3}$ | B u a n a I $1 \mathrm{mu}$ 